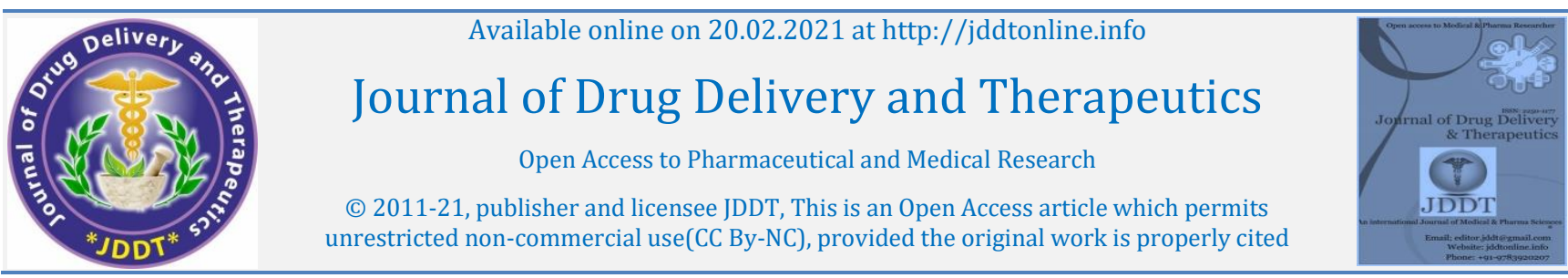

\title{
Assessment of Risk Factors and Management Associated with Preterm Deliveries and their Outcomes in Tertiary Care Teaching Hospital
}

\author{
T. Lakshmi Susheela ${ }^{1}$, Meda. Venkata Subbiah², M. Ahamadi Tabasum³ ${ }^{3}$ P. Amreen Khan ${ }^{3}$, \\ M.V. Swetha Kumari ${ }^{3}$, E. Kiranmai ${ }^{3}$ \\ ${ }^{1}$ Associate Professor and HOD, Department of Obstetrics \& Gynaecology, Govt. General Hospital-RIMS, Kadapa, Andhra Pradesh, India \\ ${ }^{2}$ Associate Professor, Department of Pharmacy Practice, P Rami Reddy Memorial College of Pharmacy, Kadapa, Andhra Pradesh, India \\ 3 (Pharm. D Intern)., P Rami Reddy Memorial College of Pharmacy, Kadapa, Andhra Pradesh, India
}

Article Info:

$\begin{array}{ll} & \text { Article History: } \\ & \text { Received 13 Dec 2020; } \\ & \text { Accepted 10 Feb 2021; } \\ & \text { Available online 20 Feb } 2021\end{array}$

Cite this article as:

Susheela TL, Subbiah MV, Tabasum MA, Khan PA, Kumari MV, Kiranmai E, Assessment of Risk Factors and Management Associated with Preterm

Deliveries and their Outcomes in Tertiary Care Teaching Hospital, Journal of Drug Delivery and Therapeutics. 2021; 11(1-s):102-107

DOI: http://dx.doi.org/10.22270/jddt.v11i1-s.4556

*Address for Correspondence:

Meda. Venkata Subbaiah, M.pharm,[Ph.D.,], Associate Professor, Department of Pharmacy Practice, P Rami Reddy Memorial College of Pharmacy, Kadapa, Andhra Pradesh, India

\section{Abstract}

Background: Preterm is a major obstetrical challenge of health care. It is the top most cause of perinatal morbidity and mortality of neonatal deaths. The births of these neonates are at a greater risk of developmental disabilities, health and growth problems than neonates of full term.

Aim and objective: To assess the risk factors and management associated with preterm deliveries and their outcomes.

Materials \& Methods: "A prospective observational cohort study" was conducted over a period of 6 months on 80 Preterm subjects, who were enrolled based on inclusion and exclusion criteria. A detailed questionnaire was used to record socio-demographic, clinical profile and prescribing management. Statistical analysis was performed by percentage method using parameters like mean, standard deviation.

Results: The impact of incidence range in the present study was $31.52 \%$. Maximum preterm deliveries were observed in the age group of 18-23 years (44\%). Multiparous woman was at more risk for preterm i.e., about 51\%. The commonest risk factor for preterm was Anemia (45\%) followed by Pre-eclampsia (24\%). The treatment prescribed for preterm was Betamethasone, Tidilon, Magnesium sulphate, Progesterone. The commonest neonatal outcome was found to be low birth weight with KMC and supplements of vitamins, iron, calcium as a therapy for their better recovery.

Conclusion: The study suggests an urgent need for strengthening effective guidelines and appropriate counselling for prevention of preterm. Maintenance of good hygiene, adequate bed rest and proper antenatal care visits for the better outcomes.

Keywords: preterm, multiparous, risk factors, neonatal outcomes, antenatal care, cohort.

\section{INTRODUCTION:}

Preterm birth additionally referred to as premature birth that states as "Babies born prematurely at intervals 24 weeks of gestation and before the 37 weeks of gestation ( $<259$ days) reckoning from morbidity the primary day of the last menstrual period" 1 . Preterm birth is the vital reason behind $75 \%$ perinatal and $>70 \%$ mortality $^{2}$. Adolescents have a higher risk of preterm birth with 19.0 and $12.7 \%$ of all births being preterm in <15-years old and 15 to 19 -years old respectively compared with slightly below $11 \%$ among women in their twenties ${ }^{3}$. India has the highest range of deaths due to PTDs accounting for $35 \%$ of neonatal deaths 4 . Moreover, the economic and social value of PTB is high as it may cause short-term and long-term consequences ${ }^{5,6}$. In concerning $50 \%$, the explanation for preterm labor isn't renowned. Hormone metabolism disorders or uteroplacental ischemia, predisposing genetic attributes ${ }^{7}$, preterm premature rupture of the membrane (PPROM) ${ }^{7,8}$, placental Previa, a previous history of preterm birth ${ }^{6}$, placental abruption9,10, recurrent UTI9,11, anemia6,8, gestational diabetes $^{8}$, pre-eclampsia and eclampsia ${ }^{7,10}$, multiparity ${ }^{7,11}$, previous cervical surgery ${ }^{8}$, oligo/polyhydramnios ${ }^{8}$, advanced maternal age ${ }^{\mathbf{1 0}}$, previous history of miscarriage and abortions ${ }^{12}$ and lifestyle habits such as smoking ${ }^{4}$, alcohol, illicit drug use are the precise risk factors of preterm births ${ }^{7}$. Birth canal infections appear to play a key role within the etiopathogenesis of premature delivery ${ }^{13}$. Maternal, fetal, or placental such as premature rupture of membranes, oligohydramnios or hydramnios, cervical incompetence, and malformation of the uterus are the complications that will occur due to preterm births ${ }^{7,1}$. Diagnosis of preterm labor relies on signs of labor, the length of the pregnancy, biochemical predictors, and ultrasound scan 1 . Bed rest, Adequate hydration suggested for preventing preterm birth 1,14. Tocolytics: Isoxsuprine hydrochloride, Nifedipine, Nitroglycerine, Oxytocin, Cervical cerclage, antenatal corticosteroids, antibiotics for PPROM, magnesium sulfate, progesterone therapy and Kangaroo Mother Care are 
recommended for reducing the outcomes of preterm birth 15,16.

\section{AIM AND OBJECTIVES:}

- To evaluate the risk factors and management of PreTerm Deliveries (PTDs) and their outcomes

- To estimate its incidence at the study site.

- To assess the management and its outcomes in PTD.

- To educate and to provide awareness among the pregnant who are at risk of preterm.

\section{METHODS:}

This was a prospective observational cohort study. A total of 80 patients were included after confirmation through physical and USG abdomen examination in Gynaecology department, Government general hospital- RIMS, a 750 bedded tertiary care teaching hospital, Kadapa. Study was done for a period of 6 months. Our Study commenced after obtaining approval from the institutional ethical committee. A written informed consent form was obtained from all participating subjects. A data collection form was used to collect all the necessary data of the study subjects. Data includes demographic details, Chief complaints, past medical \& medication history, marital history, obstetric history, height/weight, marital status, lifestyle \& habits of the patients, family history, Objective Evaluation Data (General Examination, Physical Examination, and Systemic\& Local Examination \& Lab investigations like $\mathrm{Hb}$ ), other investigations (USG), type of PTD diagnosed \& treatment provided. The clinical profile assessment form includes parameters like Age of pregnancy, parity, past obstetric history, Inter-pregnancy interval, and cervical length. For educating the subjects regarding pre-term births Information leaflet was prepared. Later the Incidence of pre-term births, commonly affected age group, common risk factors of preterm births, common neonatal complications, diagnostic procedures associated with PTD, and their management in PTDs were assessed.

The percentage method was used to analyze the subject's distribution based on various parameters by using MS Excel. The appropriate statistical parameters were used the calculate incidence of pre-term births. The statistical parameters like mean, standard deviation were used to analyze the data.

\section{Inclusion Criteria:}

$\checkmark$ Women who had consulted the gynecology department with pregnancy.

$\checkmark$ Women who had shown their eagerness to participate in the study. $\checkmark$ Women with past history or family history of PTD.

$\checkmark$ Women with less than 37 weeks of gestation.

\section{Exclusion criteria:}

Women who had not shown their willingness to participate in the study.

$\checkmark$ Women with infections like HIV.

$\checkmark$ Women beyond 37 weeks of gestation.

\section{RESULTS:}

In our study around 4,282 women have consulted the gynecology department, out of which, 135 were suspected and screened for the inclusion into the study, of them 80 were included after confirmation through physical and USG abdomen examination.

\section{INCIDENCE:}

The incidence of PTD at study site was found to be $31.52 \%$.

\section{DEMOGRAPHIC DETAILS OF THE PATIENTS:}

Table 1: Distribution of overall Demographic details from the subjects

\begin{tabular}{|l|l|}
\hline Total study subjects $=\mathbf{8 0}$ & \\
\hline Baseline characteristics & Number of subjects \\
\hline Age (years) & $65(81.25 \%)$ \\
$18-29$ & $15(18.75 \%)$ \\
$30-41$ & $34(43.5 \%)$ \\
\hline BMI & $15(19.2 \%)$ \\
Normal BMI & $8(10.2 \%)$ \\
Under BMI & $1(1.2 \%)$ \\
Over BMI & $29(37.25 \%)$ \\
Obese & $51(63.75 \%)$ \\
\hline Place of residency & $37(46.25 \%)$ \\
Urban & $43(53.75 \%)$ \\
Rural & \\
\hline Education & \\
Above primary & \\
Below primary & \\
\hline
\end{tabular}




\section{CHARACTERISTICS OF PRETERM:}

Table 2: Depicts the characteristics of preterm among the subjects

\begin{tabular}{|l|l|}
\hline VARIABLES: & NUMBER OF SUBJECTS (80) \\
\hline CLINICAL PROFILE: & $8(10 \%)$ \\
Past medical history & $72(90 \%)$ \\
Without past medical history & \\
Gestational age: & $1(1 \%)$ \\
$<28$ weeks & $17(21 \%)$ \\
$28-32$ weeks & $62(78 \%)$ \\
>32 weeks & $13(16 \%)$ \\
PAST OBSTETRIC HISTORY: & $67(84 \%)$ \\
History of abortions & $2(3 \%)$ \\
Without history of abortions & $78(97 \%)$ \\
History of miscarriage & $9(11 \%)$ \\
Without history of miscarriages & $71(89 \%)$ \\
Previous history of PTB & \\
Without history of PTB & \\
\hline DIAGNOSTIC PROFILE: & $23(29 \%)$ \\
Anemia & $48(60 \%)$ \\
Mild & $9(11 \%)$ \\
Moderate & \\
Severe & \\
\hline USG report: & $19(24 \%)$ \\
Amniotic fluid index (AFI- in cms) & $59(74 \%)$ \\
$<8$ & $2(2 \%)$ \\
$8-18$ & $43(54 \%)$ \\
$>18$ & $34(42 \%)$ \\
Cervical length (CL-in cms) & $3(4 \%)$ \\
$1.2-2.3$ & \\
$2.4-3.5$ & \\
$3.6-4.0$ & \\
\hline
\end{tabular}

\section{MANAGEMENT FOR SPECIFIC RISK FACTORS:}

Table 3: Depicts the distribution of management for specific risk factors

\begin{tabular}{|l|l|l|l|}
\hline S. NO & RISK FACTORS & EXTENT OF RISK FACTOR IN \% (N=80) & MANAGEMENT \\
\hline 1. & Anaemia & 45 & Blood transfusion \\
\hline 2. & Pre-eclampsia & 23.75 & Anti hypertensives,Magnesium sulphate \\
\hline 3. & Oligohydramnios & 17.5 & Aminoacids \\
\hline 4. & LSCS & 17.5 & Blood transfusion \\
\hline 5. & UTI & 15 & Antibiotics, Alkalisers \\
\hline 6. & PPROM & 15 & Blood transfusion, Antibiotics \\
\hline 7. & Placental previa & 10 & Blood transfusion \\
\hline 8. & Eclampsia & 7.5 & Anti hypertensives, Magnesium sulphate \\
\hline 9. & Twins & 6.25 & Blood transfusion \\
\hline 10. & IUGR & 5 & Blood transfusion \\
\hline 15. & GDM & 2.5 & Anti-diabetic drugs \\
\hline 11. & Polyhydramnios & 1.25 & Blood transfusion \\
\hline 12. & HELLP syndrome & 1.25 & Anti-hypertensives, magnesium sulphate \\
\hline 13. & Threatened preterm & 1.25 & Progesterone therapy \\
\hline 14. & Hypothyroidism & 1.25 & Anti-thyroid drugs \\
\hline
\end{tabular}




\section{MANAGEMENT OF PRETERM}

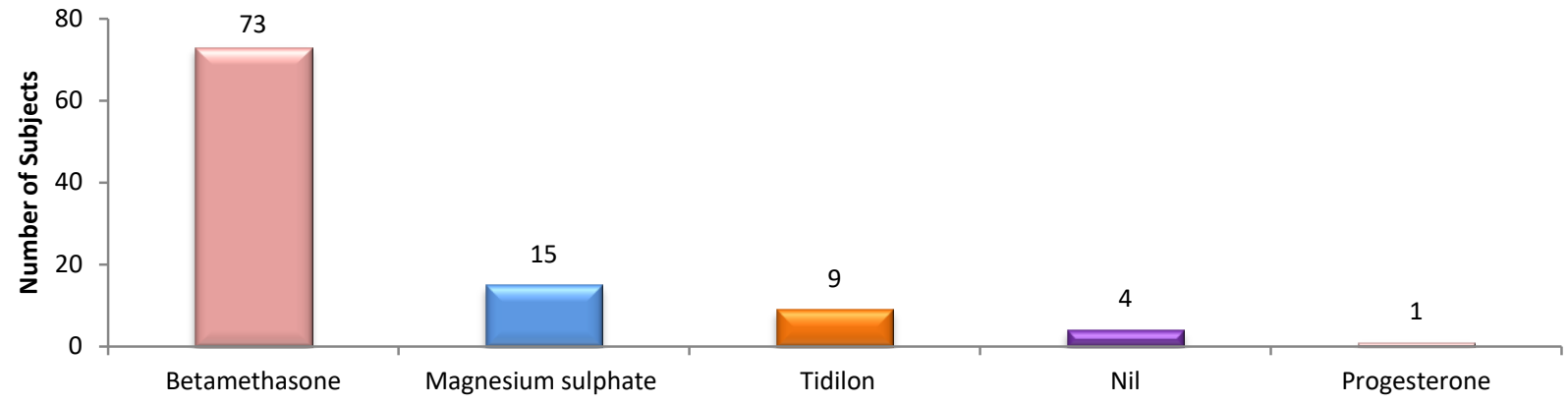

Figure 2: Distribution of subjects based On Management of Preterm

NEONATAL COMPLICATIONS:

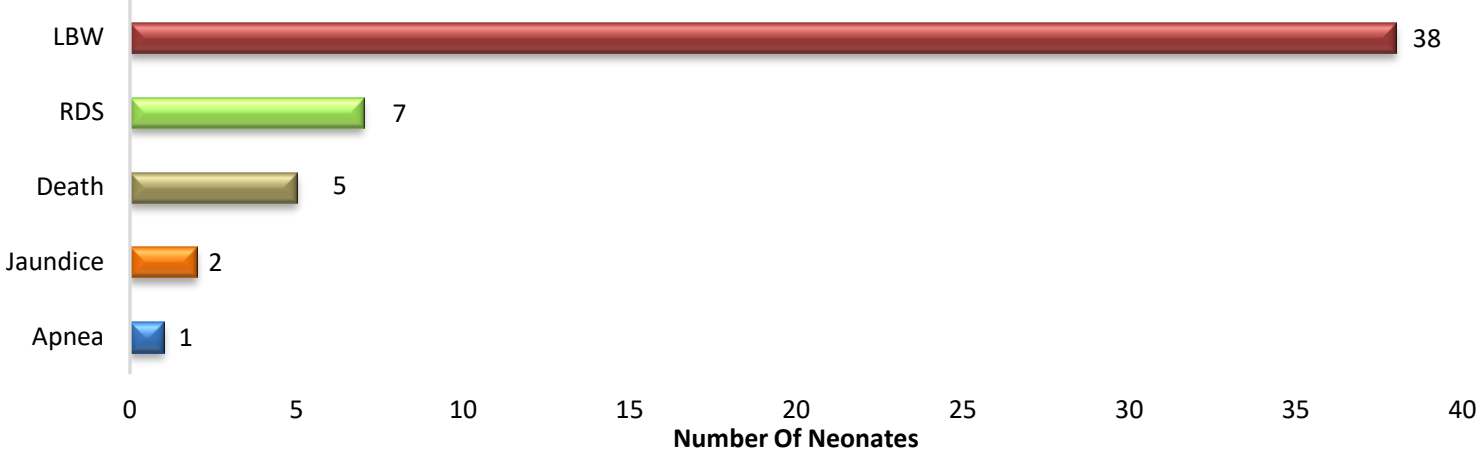

Figure 3: Illustrates the dominant complications in neonates

MANAGEMENT GIVEN FOR NEONATAL COMPLICATIONS:

Table 4: Distribution of neonates with specific management to their Complications

\begin{tabular}{|l|l|l|l|}
\hline S.No. & Complication & Management & $\begin{array}{l}\text { Number of } \\
\text { Neonates }\end{array}$ \\
\hline 1 & LBW & O $_{2}$ Inhalation, Vitamin k & 4 \\
\hline 2 & LBW & Paladai feeds, Calcimax, Vitamin D3 & 7 \\
\hline 3 & LBW & Paladai feeds, Calcimax, Vitamin D3, Zincovit & 4 \\
\hline 4 & LBW, RDS & $\begin{array}{l}\text { Paladai feeds, Calcimax, Vitamin D3, Zincovit, Nasoclear, Caffine, Rantac, } \\
\text { KMC(kangaroo mother care) }\end{array}$ & 1 \\
\hline 5 & $\begin{array}{l}\text { Jaundice, LBW, } \\
\text { RDS }\end{array}$ & Phototherapy, Paladai feeds, Calcimax, Vitamin D3, Zincovit, Nasoclear, Caffine & 1 \\
\hline 6 & Jaundice & Phototherapy, Vitamin k, Intra Gastric Feeding & 1 \\
\hline 8 & RDS, Apnea & Paladai feeds, Vitamin D3, Nasoclear drops & 1 \\
\hline 9 & LBW & Vitamin k, KMC(kangaroo mother care) & 1 \\
\hline 10 & LBW,RDS & Vitamin K, O 2 inhalation, Dextrose10\%, Taxim & 1 \\
\hline 11 & LBW & Vitamin. k, Zinc, Vitamin D3, KMC (kangaroo mother care) & 1 \\
\hline 12 & LBW & Vitamin K, zinc, Vitamin D3, Calcimax, KMC(kangaroo mother care) & 1 \\
\hline 13 & LBW, RDS & $\begin{array}{l}\text { Vitamin k, zinc, Vitamin D3, Calcimax, nasoclear drops, } 0_{2} \text { inhalation, } \\
\text { KMC(kangaroo mother care),Intra Gastric Feeding }\end{array}$ & 3 \\
\hline 14 & LBW & Vitamin.K, Amikacin, Rantac, vitamin D3,Calcimax,Taxim,Paracetamol & 1 \\
\hline 15 & LBW & Vitamin.K,O2 Inhalation ,zinc, calcimax, KMC(kangaroo mother care) & 4 \\
\hline
\end{tabular}

\section{DISCUSSION:}

Preterm births remain one in every of the foremost serious and significant obstetric problem. Efforts to predict and prevent the occurrence of preterm birth are difficult because of our lack of understanding of the chemical mechanism of labor and also the multiplicity of medical and socioeconomic factors related to preterm birth which showed similarity conducted by Miskatul Mustafa Mishu et al ${ }^{7}$. In our study, the incidence rate of PTD is $31.52 \%$ which showed similarity conducted by Shaveta Garg et al ${ }^{12}$ reported an incidence of $11.16 \%$.

In our study period, the more premature deliveries were within the age group of 18-29 years, i.e., around 65 (81\%) and this coincides with studies conducted by Shehla Jamal et $\mathbf{a l}^{\mathbf{1 3}}$ as they reported that maximum preterm deliveries occur within the age group of teenagers and elderly. In this study, we observed that more premature deliveries within the normal-weight woman having $18.5-24.9 \mathrm{~kg} / \mathrm{m} 2$, i.e., around $49(61 \%)$ and it had been supported by a study of 
Anna Clara F. Vieira et $\mathbf{a l}^{\mathbf{1 7}}$ as they describe that woman weighing $23.6 \mathrm{~kg} / \mathrm{m} 2$ are more liable to PTD. In this study, we observed the more premature deliveries from rural areas i.e., around 51 (64\%), this data supported by the studies conducted by Mahajan et $\mathbf{a l}^{\mathbf{6}}$ as they describe that women from rural areas are at the risk of PTD than urban. We observed more premature deliveries within the subjects with below primary education, i.e., around 43(54\%), this data supported the study conducted by Poonam Trivedi et $\mathbf{a l}^{4}$ as they describe that literature is one of all the barriers to the progress of premature deliveries. [Table-1]

In this study, we observed more premature deliveries i.e., around $69 \%$ of subjects with no past medical history and this data doesn't accept as true with the study conducted by Sarah Vause et $\mathbf{a l}^{\mathbf{1 8}}$, as they summarize that previous medical record is one in all the risks factors for PTDs.

In our study majority (78\%) were late PTDs, and these findings are correlated with the studies conducted by Shaveta Garg et al $^{12}$ and Farhin Radhanpuri'19 as they showed that women with a gestation of $>34$ weeks or quite woman with 28-30 weeks. Around $16 \%$ of our study subjects have undergone abortions and this study correlates with Mahajan et $\mathbf{a l}^{\mathbf{6}}$ concluded that women $(25 \%)$ with a history of abortions were at more risk for PTDs. We found that the majority of the women were having no history of miscarriage and only 2 women had a history. So, miscarriage isn't a reason/risk factor for PTDs in our study subjects. But studies conducted by Sarah Vause et al ${ }^{\mathbf{1 8}}$ and C. OliverWilliams et $\mathbf{a l}^{20}$ said that the presence of a previous history of miscarriage is one of all the dangerous factors to occur PTD.

In our study, $14 \%$ had a history of PTD, our findings correlate to the study conducted by Mahajan et $\mathbf{a l}^{\mathbf{6}}$ as they concluded that women with PTD history are at more risk for PTDs than term deliveries. We observed majority (44\%) of the study subjects were diagnosed with low hemoglobin level i.e. $\leq 8 \mathrm{gm} / \mathrm{dl}$. Hence our findings are kind of like the study conducted by Farhin Radhanpuri ${ }^{19}$ as they concluded that women with the presence of moderate anemia were at high risk for PTDs. In our study, $17.5 \%$ of the subjects were found with oligohydramnios with an AFI of $<8 \mathrm{~cm}$ and $1.25 \%$ were with polyhydramnios (AFI $>18 \mathrm{~cm}$ ) and is correlated with the study conducted by Mahajan et $\mathbf{a l}^{\mathbf{6}}$ reported that $14 \%$ of their subjects were having oligohydramnios and polyhydramnios.

As per our study, we observed that the cervical length of maximum subjects is low (54\%) i.e., between $1.2-2.3 \mathrm{~cm}$. Our data is coinciding with the study administered by Kristen Rundell et $\mathbf{a l}^{\mathbf{1 6}}$ as they reported that a shorter cervix $(<2.5 \mathrm{~cm})$ is one of the riskiest of preterm. [Table-2]

In our study, common risk factors among our subjects include anemia (45\%) were prescribed with blood transfusion who was in danger and this data coincides with the study conducted by Farhin Radhanpuri et al ${ }^{19}$. Antihypertensives and prophylactic Magnesium sulfate were prescribed for preeclampsia women (24\%), these findings are associated with the study conducted by Baha M. Sibai et $\mathbf{a l}^{21}$ as they said that prophylactic magnesium sulfate improves the neuronal development of the fetus and prevents seizures. Arginine, alanine, and amino acid infusions were prescribed for oligohydramnios $(17 \%)$ to elevate the AFI thereby promotes the maternal nutrition status, thus improves the fetal growth and this data coincides with the studies conducted by Ashima Taneja et $\mathbf{a l}^{22}$ as they reported that amino acid infusions are needed to for the higher neonatal outcomes.
Blood transfusion was prescribed for the subjects with LSCS (17\%), to prevent excessive blood loss and this data correlates with the study done out by Fatima M. Akinlusi et $\mathbf{a l}^{\mathbf{2 3}}$ as they describe that a blood transfusion may recover the pregnant from massive bleeding. UTI (15\%) will be treated with antibiotics, alkaliser, antispasmodic, as these can decrease the infection, reduce the acidic nature of the urine, burning micturition, and reduces the symptoms like leaking of urine respectively, this data correlated with the study carried out by Oscar Storms et al ${ }^{\mathbf{2 4}}$. Antibiotics and blood transfusion was prescribed for PPROM (15\%), placental previa (10\%), and these findings are correlated with the study administered by $\mathbf{N}$ Medley et al25, Lawrence Oppenheimer et $\mathbf{a l}^{\mathbf{2 6}}$ as they said that antibiotics are needed for PPROM, placental previa respectively. Eclampsia (7\%) can be treated by antihypertensives and magnesium sulfate and these findings are associated with the study conducted by Baha M. Sibai et $\mathbf{a l}^{\mathbf{2 1}}$ as they reported that it should decrease the elevated blood pressure level and scale back the tone of the myometrium.

IUGR (5\%) may cause retardation of fetal development because of reduction of blood supply and this data was the same as the study carried out by Deepak et $\mathbf{a l}^{27}$ as they reported that IUGR may result because of malnutrition and ends up in restriction of the fetus, so there is a desire of blood transfusion. Antidiabetics like insulin were prescribed for Gestational Diabetes Mellitus (2\%) and this data correlates with the study conducted by David $\mathbf{K}$ et $\mathbf{a l}^{\mathbf{2 8}}$ as they said that providing insulin may reduce the possibilities of operational deliveries in women. In our study, HELLP syndrome was managed by antihypertensives and magnesium sulfate to manage high BP and seizure activity, these findings were like the study conducted by Baha M. Sibai et $\mathbf{a l}^{\mathbf{2 1}}$ as they said that giving prophylactic magnesium sulfate may reduce the incidence of seizure. [Table-3]

In our study, prescribed management for preterm mothers includes, betamethasone as in $91 \%$ of pregnant women to enhance perinatal outcomes and this data correlates with the study conducted by Kristen Rundell et $\mathbf{a l}^{\mathbf{1 6}}$ as they said that it's going to decrease the possibilities of neonatal complications; Isoxsuprine hydrochloride in 11\%pregnant women to cause uterine relaxation and prolongs the pregnancy and this data relates with the study conducted by Vaja Pradyuman et $\mathbf{a l}^{\mathbf{2 9}}$ as they reported that it's going to delays the delivery up to $48 \mathrm{hrs}$. Magnesium sulfate is given to $19 \%$ of pregnant women to reinforce neural protection in the fetus, these findings are correlated to the study of Kristen Rundell et $\mathbf{a l}^{\mathbf{1 6}}$ as they conclude that antenatal magnesium sulfate may reduce the chance of preterm and improve neonatal development and progesterone therapy was given just for $1 \%$ of subjects to prevent the recurrent preterm. This data was supported by the study allocated by Rupsa C. Boelig et al 30. [Figure-1]

In our study, we observed the Low birth weight is the common neonatal complication i.e., around $47 \%$ and this data coincides with the studies carried out by Lerna Desalegn Hailu et $\mathbf{a l}^{\mathbf{3 1}}$ as they summarize that LBW is one of the common complications in neonates who born prematurely. Other complications found in premature neonates include apnea (1\%), RDS (9\%), deaths (6\%), jaundice $(2 \%)$, and these data findings are correlated with the study conducted by Shaveta Garg et $\mathbf{a l}^{12}$ as they reported that jaundice, RDS, neonatal morbidity were the other complications who delivered prematurely. [Figure-2]

At our study site, neonatal complications like LBW, neonatal illness were treated with KMC, paladai feeds and 02 inhalation, this study correlates with the studies conducted by Shehla Jamal et al ${ }^{13}$. Amikacin, Taxim, and Rantac were 
prescribed in 2 neonates to reduce infection and inhibit gastric acid secretion respectively, 2 were prescribed with Caffeine to stimulate effective breathing, and these findings coincided with the study carried out by Mohammed Bahari et al32. Phototherapy was advised for managing complications like jaundice and this data correlates with the studies conducted by Shehla Jamal et al13. [Table-4]

\section{CONCLUSION:}

This study concluded that preterm birth is an important reason for neonatal poor prognosis and death. The incidence rate of preterm birth was occurring in teenagers and the elderly due to several risk factors, which is due to poor literacy rate and low economic status. Low birth weight was found to be the commonest complication. Provider-initiated preterm birth can be minimized by early detection of risk factors. Therefore, early detection and treatment of a disease may reduce the risk of preterm birth. The risk of PTD and neonatal complications can manage by improving the quality of health of the mother with the help of medication. Health education, counseling will encourage pregnant women to seek antenatal care. Maintaining appropriate oral hygiene, adequate rest, and refrain from sexual activities, which may reduce the risk of preterm birth and improve better outcomes in neonates. There is a need for strengthening existing guidelines for the prevention of preterm birth and for managing neonatal outcomes.

\section{ACKNOWLEDGEMENT:}

The authors would like to thank Dr. T. Lakshmi Susheela, Associate Professor and HOD, Department of Obstetrics \& Gynaecology, Govt. General hospital-RIMS and M. Venkata Subbiah, Associate Professor, Department of Pharmacy Practice, P Rami Reddy Memorial College of Pharmacy for their effective support in this study. Authors would like to extend appreciation to individuals who were involved in data collection and thanks to all study participants who willingly give us all information that we needed.

\section{CONFLICTS OF INTERESTS:}

None

\section{REFERENCES:}

[1] Hiralal Konar. DC Dutta's Textbook of Obstetrics. $8^{\text {th }}$ Edition. New Delhi: Jayapee brothers' medical publishers; 2019: 376-379.

[2]Grace S. Chung Ryan Lawrence, MD, Kenneth A.et al "Obstetrician-gynaecologists beliefs about when pregnancy begins", American Journal of Obstetrics and Gynaecology,. 2012; 206(2):132.e1-132.e7.

[3] Lina M. Neriander, William M. Callaghan et al. "Short InterPregnancy Interval's Associated with preterm Birth in US Adolescents". Maternal Child Health Journal. 2017; 19(4):85058.

[4] Trivedi P, Saxena D et al. "A Cohort Study on Risk Factors For Preterm Birth in Rural Gujarat,"Indian Journal Of Public Health, 2018; 62(2):112-116.

[5] Lema Desalegn Hailu et al. "Determinanats of Low Birth Weight among Deliveries at a Referral Hospitalin Northern Ethiopia", International Journal of Bio Med Research, 2018; 10(1):8.

[6] Mahajan A, Magon S. "Study of risk factors for preterm births in a teaching hospital". International Journal of Medical Sciences. 2017; 6(1):1407-12.

[7] Min Jiang, Miskatul Mustafa Mishu et al. "A Case Control Study of Risk Factors and Neonatal Outcomes of Preterm Birth", Taiwanese Journal of Obstetrics and Gynaecology. 2018; 57(1):814-17.

[8] Chytra R. Rao, Parvathi Bhat, et al. "A Case Control Study On Risk Factors for Preterm Deliveries in a secondary care hospital, Southern India". ISRN Obstetrics and Gynaecology.2014; 1-5. Available from: https://doi.org/10.1155/2014/935982.
[9] Jamal S, Srivastava R, et al. "A Retrospective Analytical Study of the Epidemiology and Causes of Etiology". International Journal of Reproduction, Contraception, Obstetrics and Gynaecology.2017; 6(12):5453-57.

[10] Dhingra S, Shukla B, et al. "Preterm Labour: A Study of Etiological Risk Factors and Perinatal Outcome". International Journal of Advanced Research. 2017; 5(1):703-7.

[11] Murad M, Arbabet M, al. "Study of risk factors affecting and causing preterm birth". Journal of Entomology and Zoology Studies.2017; 5(2):406-9.

[12] Garg S, Kaur T, et al. "A study of etiology and outcome of preterm birth at a tertiary care centre". International Journal of Reproduction, Contraception, Obstetrics and Gynaecology.2017; 6(1):4481-91.

[13] Koucky M, Germanova A, Hájek Z, Parizek A, et al.Pathophysiology of Preterm Labour. Research Gate Journal. Prague medical report. 2009; 110(1):13-24.

[14] Robert E Garfield, Miha Lucovnik et al. "Diagnosis and Effective Management of Preterm Labour". MGM Journal of Medical Sciences. 2014; 1(1):22-37.

[15] Rundell K, Pancha B,. "Preterm Labour: Prevention and Management". American Family Physician.2017; 95(6):367-68.

[16] Howson C.P. MV Kinney et al. March of Dimes. save the children. WHO; Born Too Soon: The global action report on prererm birth. Geneva: 2012:126.

[17] Anna Clara F. Vieira et al. "Oral, systemic and socioeconomic factors associated with preterm birth". Journal of Women and Birth. 2018; 32(1):12-16.

[18] Vause S, Johnson T. "Management of preterm labour". Archives of Disease in Childhood. 2019; 83(2):79-85.

[19] Radhanpuri F, Deepak A. et al. "Preterm Birth and Its Outcome". International Journal of Reproduction, Contraception, Obstetrics and Gynaecology. 2014; 3(1):153-57.

[20] C. Oliver-Williams et al. "Previous miscarriage and the subsequent risk of preterm birth in Scotland". BJOG. 2015; 122(11):1525-34

[21] Baha M. Sibai MD, et al. "Pre-eclampsia Evaluation and Management of Severe Preeclampsia before 34 weeks Gestation". American Journal of Obstetrics and Gynaecology. 2011; 205(3):191-98.

[22] Taneja A, Chopra I, et al. "Pregnancy Outcomes in Isolated Oligohydramnios during Second Trimester: A Case Series". Journal of Clinical and Diagnostic Research. 2017; 11(8):1-2.

[23] Fatima M. Akinlusi, Kabiru A. Rabiu et al. "Caesarean deliverrelated blood transfusion: correlates in a tertiary hospital in Southwest Nigeria". BMC Pregnancy and childbirth. 2017; 24(18):1-9.

[24] Oscar Storms, Jose et al. "Risk Factors and Predisposing Conditions for UT". Therapeutic Advances in Urology .2019; 11(1):19-28.

[25] N. Medley, B Poljak et al." Clinical guidelines for prevention and management of preterm birth: a systemic review". British Journal of Obstetrics and Gynecology. 2018; 111(10):1361-69.

[26] Lawrence Oppenheimer, MD et al. "Diagnosis and Management of Placental Previa". Journal of Obstetrics and Gynaecology. 2017; 29(3):261-66

[27] Sharma D, Shastri S, et al. Intrauterine Growth Restriction: Antenatal and Postnatal Aspects, Clinical Medicine Insights: Pediatrics. 2016; 10(1):67-83.

[28] David K. Turok MD et al. "Management of Gestational Diabetes Mellitus". American Family Physician. 2003; 68(9):1767-73.

[29] Vaja P, Goyal M, et al. "A Comparative study of Two Tocolytic agents for Inhibition of Preterm", Gujarat Medical Journal, 2014 69(1):28-31.

[30] Rupsa C. Boelig, Eva Jiang et al. "Utilisation of progesterone and cervical length screening for prevention of recurrent preterm birth". The Journal of Maternal-Fetal and Neonatal Medicine. 2018; 32:4146-153.

[31] Lema Desalegn Hailu et al. "Determinants of Low Birth Weight among Deliveries at a Referral Hospital in Northern Ethiopia". International Journal of Bio Med Research. 2018; 10:8. Available from:https://doi.org/10.1155/2018/8169615.

[32] Mohammed Bahari, Jose Carlos Adlana et al. "caffeine use for apnea of prematurity in moderate and late preterm infants: A systemic review". Journal of Clinical Neonatology. 2019; 8(3):162-65. 